\section{Kawasaki disease or Kawasaki syndrome?}

\author{
Angelo Ravelli (1) 1,2,3 Alberto Martini ${ }^{4}$
}

In the first months of COVID-19 pandemic, paediatricians were not much involved in the management of the illness. Reports from China had shown that relatively few children and adolescents were affected, and that most of those who were infected had experienced milder disease compared with adults. ${ }^{12}$ The same trend was initially seen after the spread of COVID-19 to Western countries. ${ }^{34}$

However, between April and May 2020 , a rise in the number of children and adolescents with an acute multisystem hyperinflammatory state fulfilling full or partial criteria for Kawasaki disease (KD), ${ }^{5}$ although frequently accompanied by unusual or less common symptoms, such

${ }^{1}$ Clinica Pediatrica e Reumatologia, IRCCS Istituto Giannina Gaslini, Genoa, Italy

2Dipartimento di Neuroscienze, Riabilitazione,

Oftalmologia, Genetica e Scienze Materno-Infantili

(DINOGMI), Università degli Studi di Genova, Genoa, Italy

${ }^{3}$ Sechenov First Moscow State Medical University, Moscow, Russian Federation

${ }^{4}$ Professor Emeritus, Università degli Studi di Genova, Genoa, Italy

Correspondence to Dr Angelo Ravelli, Clinica Pediatrica e Reumatologia, IRCCS Istituto Giannina Gaslini, Via G. Gaslini 5, Genova 16147, Italy; angeloravelli@gaslini.org as abdominal pain, diarrhoea and myocardial failure, was noticed in European and North American countries or regions mostly hit by the COVID-19 pandemic. ${ }^{6-9}$ A number of these children needed urgent intensive care treatment due to the development of toxic shock syndrome, leading to multiorgan failure and circulatory shock, usually of myocardial origin, and some of them had signs of macrophage activation syndrome (MAS). Markers of inflammation were elevated, with neutrophilia, prominently increased C-reactive protein, interleukin (IL)-6, D-dimer and ferritin levels, and hypoalbuminaemia. Lymphopenia and relative thrombocytopenia were often present. Management was based on the administration of antiinflammatory treatment, which included intravenous immunoglobulin (IVIG) and glucocorticoids. In some instances, IL-1, IL-6 or tumour necrosis factor inhibitors were given. Some, but not all, of these patients tested positive on swabs or serology for SARS-CoV-2 or were exposed to potential contact with a household member affected with COVID-19.

Alerts have been issued by national health authorities and paediatric scientific societies to raise awareness of this emerging syndrome in the medical community. $^{10-14}$ This condition, which has been named 'Paediatric inflammatory multisystem syndrome temporarily associated to SARS-CoV-2 infection' (PIMS-TS) in the UK, 'Multisystem inflammatory syndrome in children' in the USA and 'Multisystem inflammatory syndrome in children and adolescents with COVID19 ' by the WHO, has encountered an increasing interest within the media. National and international collaborative efforts are currently ongoing, with the aim to characterise its features and risk factors, to understand causality and to examine treatment interventions, clinical presentations, severity, outcomes and epidemiology.

The suspicion of a possible association between COVID-19 and KD was first put forward by Jones et al, ${ }^{15}$ who reported in Hospital Pediatrics on 7 April 2020 that a girl aged 6 months diagnosed and treated for classic KD tested positive for SARS-CoV-2 by reverse transcriptasepolymerase chain reaction (RT-PCR). One month later, Riphagen et $a l^{6}$ described the features of eight children with the aforementioned hyperinflammatory syndrome, which presented with clinical manifestations similar to atypical KD, together with prominent gastrointestinal symptoms, and progressed towards multiorgan involvement and severe shock, requiring admission to the Intensive Care Unit (ICU) and haemodynamic support. All children were given IVIG and four of them received methylprednisolone. One patient developed a giant coronary aneurysm. Despite 
family exposure to COVID-19 in four children, all tested negative for SARS-CoV-2 on bronchoalveolar lavage or nasopharyngeal aspirates. Six out of eight children were of Afro-Caribbean descent and one of them died.

Shortly afterwards, the characteristics of 10 children diagnosed with a KD-like disease (five with classic KD and five with incomplete features) seen in Bergamo, Italy were detailed by Verdoni et al. ${ }^{7}$ These patients were aged 2.9 to 16 years (mean 7.5) and eight of them tested positive for SARS-CoV-2 either by nasal swab or serology. Five exhibited evidence of MAS and five of KD shock syndrome. Ten were administered IVIG and eight methylprednisolone. All 10 patients recovered without sequelae, although coronary aneurysms $>4 \mathrm{~mm}$ were detected in two patients. The monthly incidence of these KD-like cases was at least 30 times greater than that observed for KD in the same region across the previous 5 years. As compared with 19 children with KD diagnosed before the start of COVID-19 epidemic, these patients were older and had higher rates of cardiac involvement, and features of MAS.

After these earlier experiences, several other case series with similar characteristics seen in various countries have been published. ${ }^{8} 9$ 16-18 The larger sample was reported by Whittaker et $a l^{17}$ who described the features of 58 children (median age 9 years, 69\% of black or Asian race) meeting the criteria for PIMS-TS admitted in eight UK hospitals between 23 March and 16 May 2020. In total, $78 \%$ of the patients had evidence of prior or current SARS-CoV-2 infection. Three clinical patterns were identified by examining the clinical course: (1) 23 children had persistent fever and elevated acute phase reactants, but no signs of organ failure or features suggestive of KD or toxic shock syndrome; (2) 29 children developed shock, often associated with clinical, echocardiographic and laboratory evidence of myocardial injury; (3) seven children fulfilled the American Heart Association (AHA) diagnostic criteria for $\mathrm{KD}^{5}$; one of them progressed to shock. When coronary artery aneurysms were considered, a total of 13 children met the criteria for KD. Treatment included IVIG in $71 \%$ of the patients, glucocorticoids in $64 \%$ and inotropic support in $47 \%$. Eight patients received infliximab and three anakinra; $22 \%$ of the patients recovered with supportive care alone. Comparison of patients with PIMS-TS to pre-COVID-19 patients with KD and KD shock syndrome revealed differences in clinical and laboratory features, namely older age, greater elevation of inflammatory parameters and lower lymphocyte counts and haemoglobin.

In this issue of the journal, Pouletty et al ${ }^{19}$ describe the features of a further cluster of 16 patients seen in the Paris area between March and April 2020. Ten (71\%) patients met the AHA criteria for complete $\mathrm{KD},{ }^{5}$ $13(81 \%)$ had gastrointestinal symptoms, 7 (44\%) had myocarditis and 7 (44\%) and $2(28 \%)$ met the criteria for toxic shock syndrome $^{20}$ and MAS, ${ }^{21}$ respectively. Eleven (69\%) patients tested positive for SARS-CoV-2, and the remaining five had a recent contact with a family member with proven or suspected COVID-19. Ten (63\%) patients were successfully treated with IVIG, whereas five required second-line treatment, including a second infusion of IVIG, glucocorticoids, anakinra and tocilizumab. Around two-third of the patients were of Afro-Caribbean origin and no fatalities were recorded. An age older than 5 years and a ferritin level greater than $1400 \mathrm{ng} / \mathrm{mL}$ were associated with a higher risk for ICU admission. This cohort differed from a comparator sample of 'classic' KD for an older age at onset, a lower platelet count and a higher rate of myocarditis and of resistance to the first IVIG course.

Pouletty et $a l^{19}$ as well as other authors ${ }^{9} \quad 17 \quad 18$ wondered whether this hyperinflammatory syndrome represents a novel entity with respect to KD. The vast majority of patients so far reported exhibited, in a complete or incomplete form, the classical features of $\mathrm{KD}$. The main differences were an older age at onset, a higher incidence of severe myocarditis and toxic shock syndrome and a higher percentage of patients requiring further therapy after the initial IVIG infusion. Myocardial failure, toxic shock syndrome and MAS have all been reported in KD, but are usually observed in only about $5 \%$ of patients. ${ }^{52}$ They are often associated with more severe laboratory markers of inflammation, and are more likely to be resistant to IVIG therapy and to require additional anti-inflammatory treatment. So, what seems to characterise SARSCoV-2-associated Kawasaki-like disease is mainly the higher frequency of severe symptoms, rather than specific clinical features.

The aetiology of $\mathrm{KD}$ is unknown, but it is generally considered the consequence of an abnormal immune response, in genetically predisposed children, to infectious triggers entering through the upper respiratory tract. Multiple infectious agents have been suspected over the years, including respiratory RNA virus, but none has been confirmed in subsequent studies. ${ }^{5}$ In the case of SARS-CoV-2-associated Kawasaki-like disease, the onset of the disease appears to occur a few weeks after acute infection or exposure, suggesting that SARS-CoV-2 might act as a trigger of a postinfectious inflammatory disease.

Autoinflammatory diseases have taught us that many rheumatic conditions may well represent syndromes rather than diseases. A monogenic illness can, indeed, mimic the clinical features of polyarteritis nodosa, ${ }^{23}{ }^{24}$ Behcet disease, ${ }^{25}$ rheumatoid factor positive polyarthritis, ${ }^{26}$ systemic juvenile idiopathic arthritis ${ }^{27}$ and systemic lupus erythematosus. ${ }^{28}$ Thus, many of what we have called diseases are in fact syndromes presumably representing a sort of funnel, a stereotyped way of reaction of our body to multiple different aetiological factors. The recognition of the aetiology may be of utmost importance for treatment, as exemplified by the dramatic therapeutic effect of anti-tumour necrosis factor agents in case of polyarteritis nodosa associated with adenosine deaminase 2 (ADA2) mutation. ${ }^{29}$

Henoch-Schoenlein purpura, the most common form of vasculitis in children, is also a syndrome. It is often preceded by a respiratory tract infection and multiple case studies have suggested a correlation with virtually all respiratory pathogens. ${ }^{30}$ Although usually a benign disease, it can occasionally cause severe involvement of the kidney, gastrointestinal tract and central nervous system.

The occurrence of a Kawasaki-like disease in association with SARS-CoV-2 infection suggests that also $\mathrm{KD}$ is not a disease, but rather a syndrome, whose main features depend on the type of the immune response as well as on the characteristics of the triggering infectious agent. Recognition of the aetiological trigger is important since Kawasaki syndrome secondary to SARS-CoV-2 infection appears to be more severe and requires aggressive treatment.

\section{Handling editor Josef S Smolen}

Contributors We confirm that both authors have contributed in the generation of the manuscript.

Funding The authors have not declared a specific grant for this research from any funding agency in the public, commercial or not-for-profit sectors.

\section{Competing interests None declared.}

Patient and public involvement Patients and/ or the public were not involved in the design, or conduct, or reporting or dissemination plans of this research.

\section{Patient consent for publication Not required.}

Provenance and peer review Commissioned; internally peer reviewed. 
This article is made freely available for use in accordance with BMJ's website terms and conditions for the duration of the covid-19 pandemic or until otherwise determined by BMJ. You may use, download and print the article for any lawful, non-commercial purpose (including text and data mining) provided that all copyright notices and trade marks are retained.

(C) Author(s) (or their employer(s)) 2020. No commercial re-use. See rights and permissions. Published by BMJ.

\section{D) Check for updates}

To cite Ravelli A, Martini A. Ann Rheum Dis 2020;79:993-995.

Received 10 June 2020

Accepted 13 June 2020

Published Online First 22 June 2020

\section{GLinked}

- http://dx.doi.org/10.1136/annrheumdis-2020217960

Ann Rheum Dis 2020;79:993-995

doi:10.1136/annrheumdis-2020-218110

\section{ORCID ID}

Angelo Ravelli http://orcid.org/0000-0001-9658-0385

\section{REFERENCES}

1 Lu X, Zhang L, Du H, et al. SARS-CoV-2 infection in children. N Engl J Med 2020;382:1663-5.

2 Dong Y, Mo X, Hu Y, et al. Epidemiology of COVID-19 among children in China. Pediatrics 2020;145:e20200702

3 Castagnoli R, Votto M, Licari A, et al. Severe acute respiratory syndrome coronavirus 2 (SARS CoV-2) infection in children and adolescents: a systematic review. JAMA Pediatr 2020. doi:10.1001/ jamapediatrics.2020.1467. [Epub ahead of print: 22 Apr 2020].

4 Tagarro A, Epalza C, Santos M, et al. Screening and severity of coronavirus disease 2019 (COVID-19) in children in Madrid, Spain. JAMA Pediatr 2020:e201346.

5 McCrindle BW, Rowley AH, Newburger JW, et al. Diagnosis, treatment, and long-term management of Kawasaki disease: a scientific statement for health professionals from the American heart association. Circulation 2017;135:e927-99.

6 Riphagen S, Gomez X, Gonzalez-Martinez C, et al. Hyperinflammatory shock in children during COVID-19 pandemic. Lancet 2020:395:1607-8.

7 Verdoni L, Mazza A, Gervasoni A, et al. An outbreak of severe Kawasaki-like disease at the Italian epicentre of the SARS-CoV-2 epidemic: an observational cohort study. Lancet 2020;395:1771-8.

8 Licciardi F, Pruccoli G, Denina M, et al. SARS-CoV-2induced Kawasaki-like hyperinflammatory syndrome: a novel COVID phenotype in children. Pediatrics 2020:e20201711.

9 Belhadjer Z, Méot M, Bajolle F, et al. Acute heart failure in multisystem inflammatory syndrome in children (MIS-C) in the context of global SARSCoV-2 pandemic. Circulation 2020. doi:10.1161/ CIRCULATIONAHA.120.048360. [Epub ahead of print: 17 May 2020].

10 European Centre for Disease Prevention and Control. Rapid risk assessment: paediatric inflammatory multisystem syndrome and SARS -CoV-2 infection in children, 2020. Available: https://www.ecdc. europa. eu/en/publications-data/paediatricinflammatorymultisystem-syndrome-and-sarscov-2-rapid-riskassessment [Accessed 10 Jun 2020].

11 Royal College of Paediatrics and Child Health. Guidance: paediatric multisystem inflammatory syndrome temporally associated with COVID-19. Available: https://www.rcpch.ac.uk/resources/ guidance-paediatric-multisysteminflammatorysyndrome-temporally-associatedcovid-19 [Accessed 10 Jun 2020].

12 World Health Organization. Multisystem inflammatory syndrome in children and adolescents with COVID-19, 2020. Available: https://www.who. int/publicationsdetail/multisystem-inflammatorysyndrome-in-childrenand-adolescents-withcovid-19 [Accessed 10 Jun 2020].

13 Centers for Disease Control and Prevention. Emergency preparedness and response: health alert network, 2020. Available: https://emergency.cdc.gov/ han/2020/han00432.asp [Accessed 10 Jun 2020].

14 Istituto Superiore di Sanit COVID-19 Rare Diseases Working Group. Interim guidance on Kawasaki disease and acute multisystem inflammatory syndrome in children and adolescents in the current emergency scenario of SARS-CoV-2 infection, 2020. Available: https://www.iss.it/documents/20126/0/Rapporto+ISS+ COVID-19+n.+29+EN+\%281\%29.pdf/5b55fb815868-f0be-203b-63eba68fd6d8?t=1591173045788 [Accessed 10 Jun 2020].

15 Jones VG, Mills M, Suarez D, et al. COVID-19 and Kawasaki disease: novel virus and novel case. Hosp Pediatr 2020;10:537-40.

16 Rauf A, Vijayan A, John ST, et al. Multisystem inflammatory syndrome with features of atypical Kawasaki disease during COVID-19 pandemic. Indian J Pediatr 2020. doi:10.1007/s12098-020-03357-1. [Epub ahead of print: 28 May 2020].

17 Whittaker E, Bamford A, Kenny J, et al. Clinical characteristics of 58 children with a pediatric inflammatory multisystem syndrome temporally associated with SARS-CoV-2. JAMA 2020. doi:10.1001/jama.2020.10369. [Epub ahead of print: 08 Jun 2020].

18 Cheung EW, Zachariah P, Gorelik M, et al. Multisystem inflammatory syndrome related to COVID-19 in previously healthy children and adolescents in New York City. JAMA 2020. doi:10.1001/jama.2020.10374. [Epub ahead of print: 08 Jun 2020].

19 Pouletty M, Borocco C, Ouldali N, et al. Paediatric multisystem inflammatory syndrome temporally associated with SARS-CoV-2 mimicking Kawasaki disease (Kawa-COVID-19): a multicentre cohort. Ann Rheum Dis 2020:79:1000-7.

20 Kanegaye JT, Wilder MS, Molkara D, et al. Recognition of a Kawasaki disease shock syndrome. Pediatrics 2009;123:e783-9.

21 Ravelli A, Minoia F, Davì S, et al. 2016 classification criteria for macrophage activation syndrome complicating systemic juvenile idiopathic arthritis: a European League against Rheumatism/American College of Rheumatology/Paediatric rheumatology international trials organisation collaborative initiative. Ann Rheum Dis 2016;75:481-9.

22 Natoli V, Rosina S, Ravelli A. Is macrophage activation syndrome in Kawasaki disease underrecognized? Rheumato/ 2020. doi:10.3899/jrheum.200361. [Epub ahead of print: 01 Jun 2020].

23 Zhou Q, Yang D, Ombrello AK, et al. Early-Onset stroke and vasculopathy associated with mutations in ADA2. N Engl J Med 2014;370:911-20.

24 Navon Elkan P, Pierce SB, Segel R, et al. Mutant adenosine deaminase 2 in a polyarteritis nodosa vasculopathy. N Engl J Med 2014;370:921-31.

25 Zhou Q, Wang H, Schwartz DM, et al. LossOf-Function mutations in TNFAIP3 leading to A20 haploinsufficiency cause an earlyonset autoinflammatory disease. Nat Genet 2016;48:67-73.

26 Watkin LB, Jessen B, Wiszniewski W, et al. Copa mutations impair ER-Golgi transport and cause hereditary autoimmune-mediated lung disease and arthritis. Nat Genet 2015;47:654-60.

27 Wakil SM, Monies DM, Abouelhoda M, et al. Association of a mutation in LACC1 with a monogenic form of systemic juvenile idiopathic arthritis. Arthritis Rheumatol 2015:67:288-95.

28 Malattia C, Martini A. Paediatric-onset systemic lupus erythematosus. Best Pract Res Clin Rheumatol 2013;27:351-62.

29 Caorsi R, Penco F, Grossi A, et al. Ada2 deficiency (DADA2) as an unrecognised cause of early onset polyarteritis nodosa and stroke: a multicentre national study. Ann Rheum Dis 2017;76:1648-56.

30 Weiss PF, Klink AJ, Luan X, et al. Temporal association of Streptococcus, Staphylococcus, and parainfluenza pediatric hospitalizations and hospitalized cases of Henoch-Schönlein purpura. J Rheumatol 2010;37:2587-94. 